Revue musicale OICRM

\title{
Parameters of Stretto Use inside the Contrapunctus 5 of the Art of Fugue by Johann Sebastian Bach (BWV 1080, 5)
}

\section{Konstantinos G. Alevizos}

Volume 6, numéro 1, 2019

URI : https://id.erudit.org/iderudit/1062432ar

DOI : https://doi.org/10.7202/1062432ar

Aller au sommaire du numéro

\section{Éditeur(s)}

Observatoire interdisciplinaire de création et recherche en musique (OICRM)

\section{ISSN}

2368-7061 (numérique)

Découvrir la revue

\section{Citer cet article}

Alevizos, K. G. (2019). Parameters of Stretto Use inside the Contrapunctus 5 of the Art of Fugue by Johann Sebastian Bach (BWV 1080, 5). Revue musicale OICRM, 6(1), 142-159. https://doi.org/10.7202/1062432ar
Résumé de l'article

Dans cet article mon objectif est de tenter de connecter - en traçant les liaisons - toutes les techniques compositionnelles simultanées que Bach a employé afin de créer les différentes possibilités de stretto dans le Contrapunctus 5 de L'art de la fugue. L'analyse offre une nouvelle perspective en mettant en relation quatre éléments présents dans chaque exposition du sujet en stretto, en essayant en même temps de discerner leur logique de disposition : la distance d'entrée, la technique d'inversion, le positionnement des dux et comes ainsi que l'utilisation d'éléments rythmiques spécifiques. 


\title{
Parameters of Stretto Use inside the Contrapunctus 5 of the Art of Fugue by Johann Sebastian Bach (BWV 1080, 5) ${ }^{1}$
}

\author{
Konstantinos G. Alevizos
}

\begin{abstract}
In this article, my objective is to attempt to connect all the simultaneous compositional processes that J. S. Bach combined in order to create the stretto forms inside the Contrapunctus 5 of the Art of Fugue. The analysis offers a perspective by relating four technical elements present in every stretto of the subject; the distance of entry in each voice, the raw material used, the technique of inversion and the position of duxand comes.
\end{abstract}

Keywords: analysis; Johann Sebastian Bach; compositional techniques; fugue; stretto.

\section{Résumé}

Dans cet article mon objectif est de tenter de connecter - en traçant les liaisons toutes les techniques compositionnelles simultanées que Bach a employé afin de créer les différentes possibilités de stretto dans le Contrapunctus 5 de L'art de la fugue. L'analyse offre une nouvelle perspective en mettant en relation quatre éléments présents dans chaque exposition du sujet en stretto, en essayant en même temps de discerner leur logique de disposition : la distance d'entrée, la technique d'inversion, le positionnement des dux et comes ainsi que l'utilisation d'éléments rythmiques spécifiques.

Mots clés : analyse; Jean-Sébastien Bach ; fugue ; stretto ; techniques compositionnelles. 
When observing and studying the music of Johann Sebastian Bach, ${ }^{2}$ we may find ourselves at an impasse due to the presence of several parallel, but connected, analytical fields. The difficulty of simultaneously processing several of these fields ${ }^{3}$ makes it necessary to thoroughly and methodically examine one field before examining another. By analysing multiple facets of the music, we create a bridge of understanding among these apparently heterogeneous fields, which enables us to better comprehend the inner structure of the composition. However, these heterogeneous fields do not always interact with one another in a clear way. Despite the multiple fields of analysis, the composer may choose to focus his or her attention on one or several specific techniques in each piece. In the case of Contrapunctus, these are contrapuntal techniques.

It is well known that Bach was interested in complex compositional procedures. However, he did not leave behind any theoretical work besides his music. Nonetheless, his attitude towards these procedures can be documented in many ways. For example, only some of the ways Bach uses numbers in his music include the total number of bars of a composition (or of the inner parts of it), ${ }^{4}$ the number of times that a motif is repeated inside a work, ${ }^{5}$ the total number of notes inside a specific subject, the symmetry and proportion inside a series of compositions represented by numbers, ${ }^{6}$ and the application of Smend's number alphabet; there are a multitude of other ways beyond the scope of this article (Houten and Kasbergen 2003; Tatlow 1991, 2015). Furthermore, many of these studies offer different points of view regarding the use of numbers inside Bach's music. Consequently, Bach's music output has been examined through Pythagorean (Dentler 2000), theological (Göncz 2012) and occasionally, esoteric and symbolic lenses. The mere transliteration of numbers inside Bach's music is of less importance than the directed use of numerical procedures for compositional reasons.

The Art of Fugue is a series of compositions (or a composition in the form of a series, as Spitta called it) that use many compositional techniques in different ways. Perhaps the unfinished fugue (BWV 1080, 19) is the most fertile case; the use of precise technical procedures here is undisputed ${ }^{7}$ (Göncz 2013, pp. 129-130; Butler in Butler,

2 I do not use the term "listen" only because much of these examination fields are not apprehended during the listening process.

3 As an example, I could use several possible analysis approaches that can be overtaken on the structural (morphological) plan of a work, such as harmonic, rhythmic, arithmetic, rhetorical, the theological approaches, etc.

4 The Prelude and Fugue in B Minor, BWV 544, employs 33 bars (not an incidental number) for the creation of an "intermezzo" inside the fugue, beginning in A major, between bars 28 and 61.

5 One example is the Orgelbüchlein chorale Vom Himmel hoch, BWV 606, where the bass motif is repeated 14 times. The same is true for BWV 615.

6 An example of this is the two-voice inventions in BWV 771-786.

$7 \quad$ As an example, see the research of Zoltán Göncz 2013, pp. 129-130. Göncz identified the exact position of the missing fourth voice/subject for the final four-voice stretto. The research of Gregory Butler indicated the length of a fourth subject by investigating the proportions of the existing three. As far as the mirrored expositions inside the Contrapunctus 6 are concerned, I suggest Alevizos 2016, p. 210. 
Stauffer and Green 2008, pp. 119-120; Alevizos 2016, p. 210). While the research that examines the philological aspects of the work is quite abundant, equivalently detailed score analysis of the work is not available. To the best of my knowledge, the following represents the most important analytical score study of the work (Higgs 1877; Wolfgang Graeser in Bach 1926; Tovey [1931]1974; Dickinson 1950, 1956; Bitsch 1967; Chailley 1971; Wiemer 1977, 1981; Kolneder 1983; Heinrich 1983; Schleuning 1993; Vartolo 2008; Alevizos 2016).

The Art of Fugue is a musical work in which Bach explores different compositional techniques, which can stand separately, but are also organized in a climactic pattern from beginning to end. ${ }^{8}$ The use of numbers can easily be found when these techniques occur, and the aim of the current essay is to demonstrate their use for specific compositional goals and the methodological procedures that Bach uses to achieve these.

\section{CONTRAPUNCTUS 5}

Contrapunctus 5 holds the fourth position inside the manuscript $P 200$ and the fifth position inside the original editions of 1751 and 1752. Regardless of its position inside the collection, it is possible to consider this piece as an ouverture to the stretto technique within the entire work. ${ }^{9}$ This fugue differs from the fugues in the first section (fugues 1 to 4); beginning with this fugue, Bach clearly introduces the stretto technique in addition to inversion and reversion ${ }^{10}$ (Higgs 1877, p. 63). Inverted and reverted triple counterpoint are also used in some cases (Alevizos 2016, p. 210). However, Bach seriously addresses these last two compositional methods separately, namely, inside the third section (in the double fugues 9 and 10 and triple fugues 8 and 11) and fourth section (inversion and reversion, fugues 11 and 12) of the Art of Fugue. In this second section of the work (fugues 5, 6 and 7), the basic element on which the composer focuses a great deal of his attention is the stretto.

Contrapunctus 5 has a rather regular overall form, with a tendency towards symmetry. This can be seen by examining the global structure of the fugue, which consists of alternating expositions and episodes and connecting sections and canons in a rather regular and coordinated manner (Alevizos 2016, p. 309). Based on this morphological plan of the fugue, it is possible to affirm that in this fugue, Bach carefully planned the

8 The notion of progression inside the work is not new; Heinrich (1983) based his entire conception on this matter and so did Bagnal (1975) who used this concept to reorganize the first section of the work. Lester (2001) proposed the same idea to sustain the heightening levels theory.

9 Although Contrapunctus 2 of the original edition appears to present dotted rhythmic elements (derivatives of the codetta of the subject), it is known than Bach elaborated the score a second time by adding the dots to transform it into a dotted form, as Wiemer (1981) has demonstrated.

10 To the best of my knowledge, James Higgs was the first to document the difference between the inversion and reversion of a subject inside the Art of Fugue, especially regarding the "mirror" fugues. Through these means, the interval inversion of a subject differs from its voice position (reversion) inside a fugue. In a reversion, the voices are exchanged around the center axis of the score (i.e. soprano becomes bass, alto becomes tenor; see Higgs 1877, pp. 63-64). 
distance of entry of each subject exposition. The overall structure can be divided in three parts (the first part is in the tonic, the second part is a harmonic elaboration, and the third part is a re-exposition) without insinuating any meaningful link to the classic tripartite form. The use of a tripartite structure could be explained as a rhetorical gesture (Levarie and Merrick 1943, pp. 16-17). These formal decisions suggest a clear premeditated effort in the construction of the fugue. However, as far as the morphological plan of the fugue is concerned, it is possible to acknowledge parallel compositional techniques with heightening levels of activity throughout the piece. It is not possible to confirm the same arrangement for the stretti overall sequence (as we will see in the next pages). In addition, the fugue includes two four-part canonical episodes, which can be interpreted as a premonitory indication of the importance stretto will acquire in the following fugues of the collection. ${ }^{11}$ Therefore, after having accepted the progressive and accumulative predisposition of the Art of Fugue as a whole (Heinrich 1983, p. 3), it is easy to understand that the premeditation process accounts for not only the creation of Contrapunctus 5, but also its position and significance inside the entire sequence of fugues. Technically, the entire fugue is based on three types of raw material, specifically the dotted rhythm of the subject, the codetta and the rhythmic element of the anapaest (the two eighth-notes followed by a quarter note).

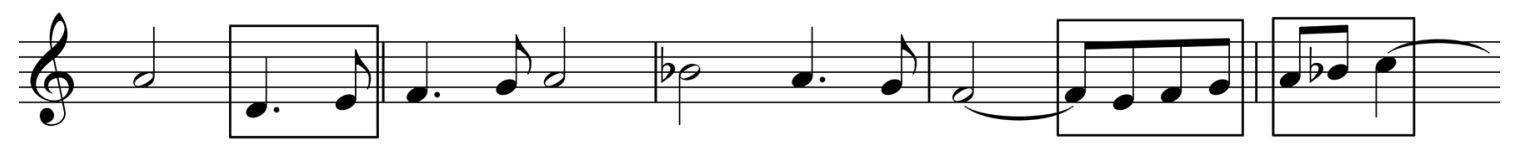

Figure 1: Contrapunctus 5, bars 1-5, alto.

We distinguish the dotted rhythm (bars 1-3) in the first part of the subject, the codetta in the second part (bar 4), and the anapaest in bar five. Among the first five fugues, this is the first time that Bach exploits many elements simultaneously (however, not insistently) inside a fugue. His habitual way of proceeding in the first section of the Art of Fugue consists of elaborating a single element. In Contrapunctus 5, the first of the second section, Bach elaborates on several elements: the stretto and the inversion techniques, the anapaest segment of the countersubject and the syncopation effect, and the codetta and the dotted segment of the subject.

Figure 2 presents the global morphological structure of Contrapunctus 5. Beyond the choice of the raw material to elaborate (rhythmic segments, etc.) or Bach's compositional methods (syncopation, inversion, etc.), this structure shows the way in which he conceived the distribution of the thematic phases within the fugue. Figure 2 is a comprehensive source of information regarding the construction of each thematic phase and its arrangement within the fugue. The table also indicates the position and structure of the episodes and canons (Ep./Can.), the harmonic scale of each

11 Although I do not intend to discuss the global structure and the ordering procedure inside the Art of Fugue, it is quite clear that Bach used the subjects of Contrapunctus 1 and 5 as basic subjects. Furthermore, inside the progressive order of the series of all fugues, Bach introduced elements of technique inside earlier fugues for exhaustive exploitation in later fugues. 
exposition of the subject, and the direction of each subject (rectus $\uparrow$ or inversus $\downarrow$ ) and its function as $d u x$ or comes. Furthermore, this table allows us to examine the internal construction of each thematic phase. A risk of interpretation exists in compiling this table because of the occasional difficulty in selecting which subject expositions to place together. Here, I attempted to consider different aspects to obtain the most accurate view of the whole. Two principal aspects create unity among apparently detached subject expositions, namely, the position of each voice inside a specific thematic phase and its distance of entry.

\begin{tabular}{|c|c|c|c|c|c|c|c|c|c|c|}
\hline v./str. & Exp. 1 & Pont & Exp. 2 & Ep. & [Exp. 3 & $(E p$ & Ep.) & Exp. 3] & Pont & {$[\operatorname{Exp} .4$} \\
\hline$S$ & $\mathbf{3 D} \uparrow$ & & $1 \mathrm{C} \downarrow$ & - & 2D $\downarrow$ & $\mathbf{A}$ & $\mathbf{A}$ & & & \\
\hline$A$ & $1 \mathrm{D} \downarrow$ & & $4 \mathrm{D} \uparrow$ & $\mathbf{A}$ & & $\mathbf{A}$ & $\mathbf{A}$ & $2(4) D \uparrow$ & & \\
\hline$T$ & $4 \mathrm{C} \downarrow$ & & $2 \mathbf{D} \uparrow$ & B & & $\mathbf{A}$ & - & $1(3) C \downarrow$ & & $2 \mathrm{D} \downarrow$ \\
\hline$B$ & $2 \mathbf{D} \uparrow$ & & 3D $\downarrow$ & $\mathbf{A}$ & $1 \mathrm{D} \uparrow$ & $\mathbf{A}$ & B & & & $1 \mathrm{D} \downarrow$ \\
\hline Distance & & 3 bars & & & & & f note & & & $\begin{array}{c}\text { Dotted } \\
\text { Whole note }\end{array}$ \\
\hline $\begin{array}{l}\text { Subject's } \\
\text { Direction } \\
\text { (R/I) } \uparrow \downarrow\end{array}$ & \multicolumn{8}{|c|}{ First group: paired alternate direction $\uparrow \downarrow$} & & $\begin{array}{l}\text { Second } \\
\text { group }\end{array}$ \\
\hline Dux/Comes & \multicolumn{3}{|c|}{ DDDC Mirror CDDD } & & \multicolumn{6}{|c|}{ DDCD Sequence } \\
\hline $\begin{array}{l}\text { Tonality of } \\
\text { Subject entry }\end{array}$ & D-D-D-A & & A-A-D-D & & F-F & & & G-G & & $\mathrm{Bb}-\mathrm{Bb}$ \\
\hline \multirow{2}{*}{$\begin{array}{l}\text { Harmonic } \\
\text { Sequence }\end{array}$} & \multicolumn{3}{|c|}{ Tonic/Dominant D-A } & & \multicolumn{6}{|c|}{ Modulation F-G-B b } \\
\hline & \multicolumn{5}{|c|}{ D-A-F triads } & & & \multicolumn{3}{|c|}{ G-B-DD triads } \\
\hline bar & $1-13$ & $14-16$ & $17-29$ & $30-32$ & $33-37$ & $37-38$ & $39-40$ & $41-45$ & $45-46$ & $47-52$ \\
\hline$v$. & Can. 1 & Exp. 4] & $E p$. & Can. 2 & [Exp. 5 & Pont & Exp. 5] & Ep./Cad. & Exp. 6/Ped & - \\
\hline$S$ & $1 \downarrow$ & $1(3) C \uparrow$ & $\mathbf{A}$ & $1 \uparrow$ & $1 \mathrm{D} \downarrow$ & & & $\mathbf{A}$ & & - \\
\hline$A$ & $3 \downarrow$ & 2(4) $D \uparrow$ & $\mathbf{A}$ & $3 \uparrow$ & & & 2(4)D $\uparrow$ & $\mathbf{B}$ & $1 \mathrm{D} \uparrow$ & - \\
\hline$T$ & $2 \downarrow$ & & $\mathbf{A}^{\prime}$ & $4 \uparrow$ & \multirow[t]{2}{*}{$2 \mathbf{D} \downarrow$} & & $1(3) \mathrm{C} \uparrow$ & $\mathbf{A}$ & & - \\
\hline$B$ & $4 \downarrow$ & & $\mathbf{B}$ & $2 \uparrow$ & & & & B' & $1 \mathrm{D} \downarrow$ & - \\
\hline Distance & \multicolumn{2}{|c|}{ Dotted Whole note } & & \multicolumn{4}{|c|}{ Whole note } & & Simultaneous & - \\
\hline $\begin{array}{l}\text { Subject's } \\
\text { Direction } \\
\text { (R/I) } \uparrow \downarrow\end{array}$ & \multicolumn{7}{|c|}{ Second group: paired parallel direction $\uparrow \uparrow \downarrow \downarrow$} & & Symmetry $\uparrow \downarrow$ & \\
\hline Dux/Comes & \multicolumn{7}{|c|}{ DDCD Sequence } & & DD & \\
\hline $\begin{array}{l}\text { Tonality of } \\
\text { Subject entry }\end{array}$ & & D-D & & D-D & & & D-D & & DD & - \\
\hline \multirow{2}{*}{$\begin{array}{l}\text { Harmonic } \\
\text { Sequence }\end{array}$} & \multicolumn{9}{|c|}{ Tonic D } & - \\
\hline & \multicolumn{2}{|c|}{ G-Bb-D triads } & & & \multicolumn{5}{|c|}{ Tonic triad } & - \\
\hline bar & $53-56$ & $57-62$ & $62-64$ & $65-68$ & $69-73$ & $74-76$ & $77-81$ & $81-85$ & $86-90$ & - \\
\hline
\end{tabular}

Figure 2: Comprehensive morphological structure of Contrapunctus 5.

Additionally, the harmonic development of the fugue differs from its morphological development, which means that the harmonic modulations do not necessarily correspond to the progression of the thematic phases. Consequently, different types of exposition can belong to the same harmonic setting, which is the case for the thematic phases in $F, G$ 
and $\mathrm{B}$, (bars 33-52). ${ }^{12}$ These subject expositions create a unity as expositions that are not in the tonic harmonic setting, and they use a different approach in terms of the distance of entry and the technique of inversion but have a similar progression method ( $d u x$ and comes, DDCD). Therefore, it is clear that to advance the understanding of the combinations among the thematic phases, it is necessary to define the basic principles of elaboration that Bach uses when he provides a specific identity to an exposition. Accordingly, it is possible to list the following elements:

a) Harmonic field of the subject and its environment;

b) Stretto (distance of entry);

c) Technique of inversion;

d) Raw material; and

e) Subject/Answer (dux/comes).

These elements are possible criteria that might have helped organize the specific stretto combinations.

\section{The Stretto Possibilities}

Donald Francis Tovey affirmed that the subject of the Art of Fugue was designed for the fugues of the second section (5, 6 and 7) and especially for Contrapunctus 5 (Tovey [1931]1974, p. 10). This is indeed true because it enabled the composer to work livelier stretto possibilities than the stretto arrangements that use the subject in its simple state (Contrapunctus 1). Additionally, it gives the composer the opportunity to work with more clarity with reversible counterpoint (Franck 2010, pp. 121-122; Bitsch and Bonfils 1981, pp. 12-13; Mann 1987, p. 271). The rhythmic structure of the simple subject (Contrapunctus 1) does not allow voices to be heard as clearly in complex stretto constructions due to its homogeneous rhythmic nature, which is based entirely on half notes. In contrast, the dotted subject (Contrapunctus 5) offers an immense variety of stretto possibilities and inversions.

Regarding the use of inversion in the Art of Fugue, Bach creates a pivot key (normally the mediant of the scale) around which the intervals are inverted. In this way, he retains the inverted construction inside a harmonic setting without the need to modulate.

\begin{tabular}{ccccc}
\hline $\mathrm{C} / \mathrm{C} \#$ & & $-\mathrm{F}-$ & & $\mathrm{B} b / \mathrm{B}$ \\
\hline $\mathrm{D}$ & & $-\mathrm{F}-$ & & $\mathrm{A}$ \\
\hline & $\mathrm{Eb} / \mathrm{E}$ & $-\mathrm{F}-$ & $\mathrm{G} / \mathrm{G} \#$ & \\
\hline
\end{tabular}

Figure 3: The creation of inversions.

12 The same operation occurs between bars 57 and 90, in which the harmonic setting is the same, but the structure of each thematic phase is different. 
Accordingly, while inverting a subject in this way, any interval can be reproduced on the pivot as a quantity and not necessarily as a quality (a quantity is simply an interval number without an interval quality, such as major or minor). Therefore, it is possible to understand that when a rectus subject in $\mathrm{D}$ minor modulates to A minor with the elevation of $G$ to $G_{\#}$ (in the dominant of $A$ minor), its inversion will not necessarily involve the flattening of $\mathrm{E}$. If this were the case, then the flattening of the E key (in $E_{b}$ ) would create a Neapolitan sixth or at least an environment in which modulation occurs towards the subdominant scale (IVth degree). Accordingly, the inversion works in the context of a single scale; otherwise, its use could create unwanted harmonic modulations. To avoid unnecessary modulations, the interval's quality is always tied to the harmonic function in a given section.

In the Art of Fugue, Bach uses two types of stretto. The first type of stretto is used within the second section (fugues 5, 6 and 7), and is the most appealing and complex stretto, following a note-by-note procedure when combining phrases. The second type of stretto combines larger subjects (including the altered subjects of the Art of Fugue ${ }^{13}$ ), which cannot be combined by using complex juxtaposition procedures. Therefore, to appreciate the most interesting use of the stretto inside the Art of Fugue, it is necessary to acquire a synoptic awareness of the second section of the work.

The construction of the subject of the fugue permits many possible stretto arrangements with different entry intervals. ${ }^{14}$ However, in the present fugue, Bach does not choose to create stretto expositions with a shorter entry-distance than that of a half note, apart from the two canon episodes. Consequently, the patterns are always multiples of half notes (half note, half note $\mathrm{x} 2, \mathrm{x} 3, \mathrm{x} 4, \mathrm{x} 5$ and $\mathrm{x} 6$, i.e., the half note, whole note, dotted whole note, etc.), although in this fugue, he does not use the double whole note as an entry distance. However, not all stretto combinations are possible, even with Bach's seemingly careful planning. The problem appears when the juxtaposition occurs between the leading tone $(\mathrm{C} \#$ in the tonic scale) and the first degree (D) or in the inverted setting, between the sixth (B, in the tonic scale) and the dominant (A) degree. The tables included in the annex can provide a more precise overview on the issue regarding the impossibility of some stretto combinations.

Figure 4 shows three stretto combinations that are not possible due to the creation of harmonic dissonances. The same result occurs in the inverted setting of these three stretti (on the mediant) with the conversion of $\mathrm{C} \#$ and $\mathrm{D}$ to $\mathrm{B}$, and $\mathrm{A}$, respectively. Thus, the reversion (reversing voice order and inverting melodic content) of the settings given in Figure 4 cannot be used either. These include the sequence of II (inversus-inversus) with a half note entry distance, II at the double whole note and IR (inversus-rectus) at the dotted whole note.

13 The subjects of fugues 8, 9, 10, 11, 12 and 19, excluding the canons, are altered.

14 In the annex of the present article, I present four comprehensive tables that include the stretto combinations of the subject in RR, II, RI and IR. The problems of the diminution and augmentation of the subject are addressed inside fugues 6 and 7. Moreover, exhaustive research on the stretto combinations demands the possibility of juxtaposing the subjects as dux or comes due to the alteration of the first note in the tonal responses. 

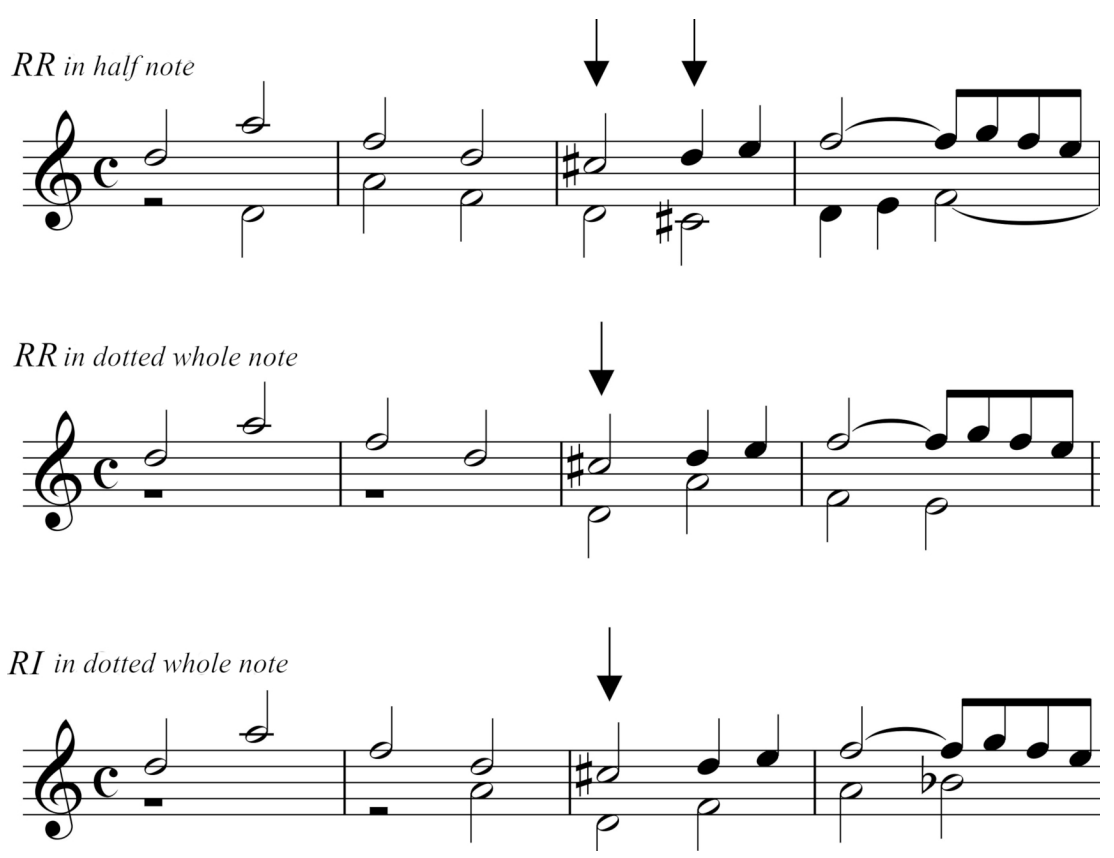

Figure 4: Non-operational stretto combinations.

However, Bach invents a solution to soften the harmonic dissonance of some stretto combinations that could not have worked with the original subject of Contrapunctus 1 . By adding dotted values to the plain subject, he creates passing notes that can resolve the harmonic dissonance. This is not always true from a strict and theoretical point of view, because the dissonant value is usually larger than the consonant value, whereas the opposite should be the case. Nonetheless, this provides a workable solution to the problem.
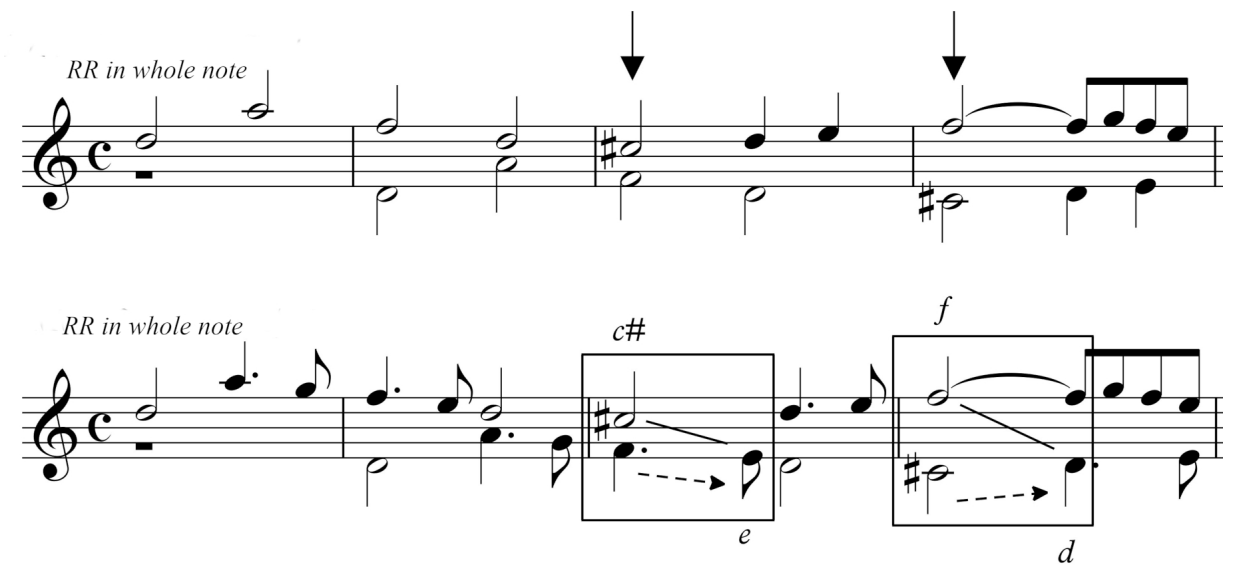

Figure 5: Avoiding dissonance in the stretto combinations of the dotted subject.

The first stretto of Figure 5 presents a combination of two entries of the plain subject with an entry distance of a whole note. This subject is probably unusable 
in this fugue ${ }^{15}$ due to the harmonic dissonance of the augmented fifth (F-C\#) and the diminished fourth $(\mathrm{C} \#-\mathrm{F})$, which creates a particularly harsh effect on the strong beat. In the second example, Bach, by using the dotted subject, succeeds in evading the first dissonant interval by using the passing note E, which creates a major sixth $(\mathrm{E}-\mathrm{C} \#)$ when the $\mathrm{F}$ resolves down. Theoretically, a problematic situation remains because the dissonant interval has a greater value than the consonant one, but to the listener, it sounds resolved. The entire collection of fugues is filled with examples of this appoggiatura effect, which lends itself to a double interpretation depending on the note that needs to resolve.

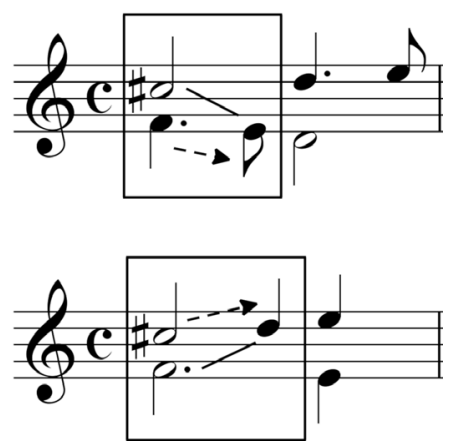

Figure 6: The two methods of the appoggiatura effect.

Whether the $F$ resolves to the $\mathrm{E}$ or the $\mathrm{C} \sharp$ resolves to the $\mathrm{D}$ depends on the composer's choice to create a dominant or tonic harmony. Thus, without the appoggiatura effect, some stretto combination are impossible to use without harmonic dissonance.

\section{EXAMination Of THE STRETTO In CONTRAPUNCTUS 5}

In Contrapunctus 5, Bach creates six separate exposition groups that all use a clearly-defined combination pattern regarding the distance of entry inside each stretto group. Bach did not conceive the global setting of the fugue as a continuous stretto device, so he did not feel the necessity to progressively decrease the distance of the subjects' entries. This explains the non-progressive (non-decreasing) stretto behaviour of the thematic phases (Tovey [1931]1974, p. 11). In fact, after the second exposition group (bars 33-45), which employs the half note as an entry distance, Bach uses the dotted whole note for the exposition group that follows (bars 47-62). The continuously decreasing stretto distances, as in a typical fugue stretto structure, only begins in bar 72 with the use of eighth notes in the bass line. This also explains the non-typical use of the tenor twice inside a single thematic phase (bars 69-77). In this case, Bach decides to sacrifice the correct order of the voices in the $\mathrm{S}-\mathrm{T}-\mathrm{A}-\mathrm{B}$ exposition by changing the order to $\mathrm{S}-\mathrm{T}-\mathrm{A}-\mathrm{T}$. This allows the melodic line of the bass to take

15 Bach reveals all the stretto possibilities of the dotted subject progressively but mostly in Contrapunctus 7, where he presents the stretti in "Rectus, Inversus, per Augmentationem et Diminutionem" and in its normal state for three voices and in reversion. 
auditory precedence inside the beginning of the stretto progression, compared to the voice entry.

It appears that Figure 2 creates more questions than it resolves, mainly because the morphological structure of the fugue can be defined in many ways according to the principle that underlies the division, and the most common principle is the entry distance of the voices. Moreover, this principle automatically considers the matching of the position of the voices in each exposition group. The third, fourth and fifth expositions (Figure 2) simultaneously consider the correct position of the voices and the entry distance but do not match the inversion symmetry. This is because expositions 1, 2 and 3 use an alternating method regarding the inversion $(\downarrow \uparrow \uparrow \downarrow-\downarrow \uparrow \downarrow \uparrow$ - $\downarrow \downarrow \uparrow$ or IRRI - IRIR - RIIR), but beginning from exposition 4 (expositions 4 and 5), the inversion occurs in parallel pairs $\downarrow \downarrow \uparrow \uparrow-\downarrow \downarrow \uparrow \uparrow$. Therefore, it is necessary to admit the impossibility of combining three elements that may have defined the structure of the expositions, specifically, the entry distance, voice position and inversion.

I could extend this operation by examining the presence of a possible systematic arrangement of $d u x$ and comes inside the exposition groups, a puzzle that Chailley (1971) attempted to resolve regarding the entire Art of Fugue. In this way, the coexistence of four elements would create an even more complex combination system. However, regarding the dux and comes, the plan appears to be quite conceivable; the fugue is divided into two parts: one part that uses the DDDC (and in mirror, CDDD) combination (expositions 1 and 2), and another part that uses the DDCD combination (expositions 3, 4 and 5).
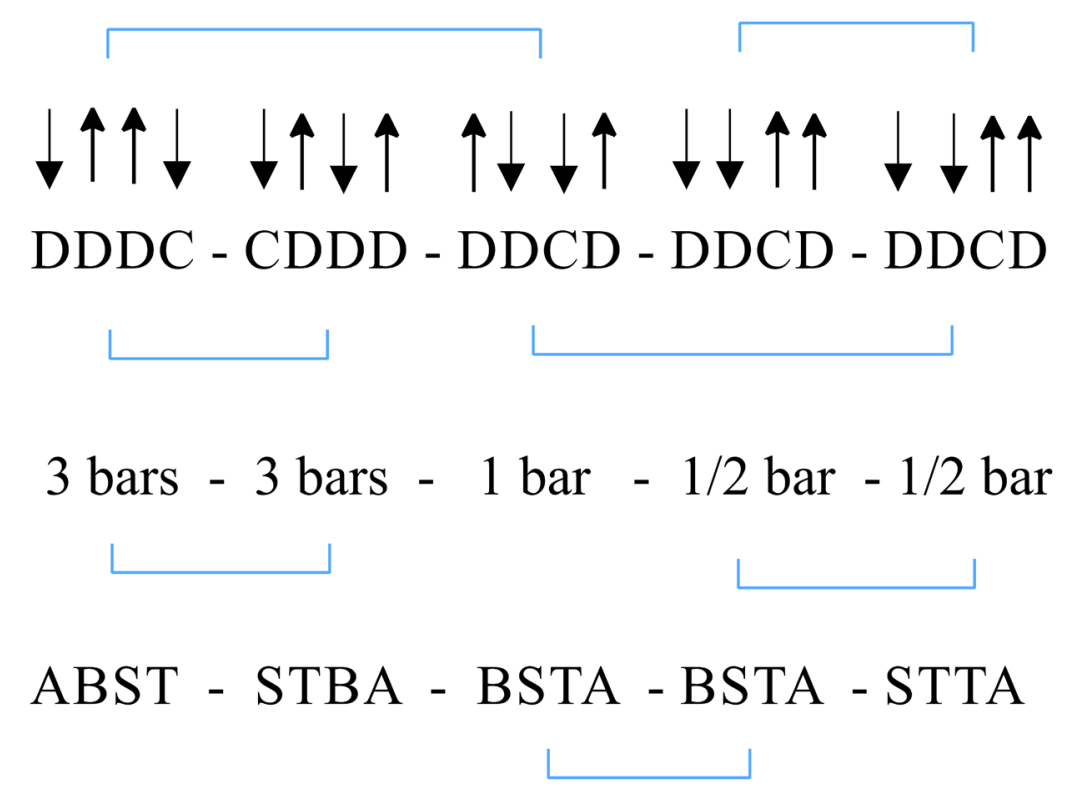

Figure 7: Combination of the four elements.

Apparently, the combination of these four elements does not provide any satisfying pattern that suggests a system or a premeditated method of composition regarding the fugue. However, this demonstrates the composer's careful consideration in parallel and simultaneous technical fields of exploration within the compositional 
process. Principally, Bach applies systematic procedures at different levels (fields) of the composition without implying a premeditated interconnected structure between these levels. The parts that unify the structure of Contrapunctus 5 probably do not interact isomorphically with these elements. Although the existence of a compositional method that encompasses the entire series of fugues seems possible, it is thus difficult to say that the same is true for the construction of each fugue. This is not necessarily the case because it does not exist but rather because it is very difficult to recognise. Regarding this last issue, many important and indisputable discoveries have been made in recent decades that have examined precise technical procedures. These include the presence of the segmented countersubject in Contrapunctus 2 within the so-called simple fugues (Rivera 1978, p. 345), the transformation to the dotted theme in the same fugue (Wiemer 1981, p. 416), the study of proportions regarding the length of the unfinished fugue (Butler 1983, p. 56), the compositional plan of the same fugue (Göncz 1991, p. 115), and the presence of mirrored entries inside Contrapunctus 6 (Alevizos 2016, p. 210).

All of these works identify a precise technique or systematic plan that aims at a specific result, while also exploiting the use of arithmetical and compositional procedures. Nevertheless, in attempting to identify the reasons that led the composer to one choice over another regarding the use of a specific technique, we are led to considerations of the composer's subjective choices. The use of elaboration of the stretto forms inside this Contrapunctus of the Art of Fugue is not a mere application of an extra-musical concept that enters the musical score through numbers. This stretto use is but one of many compositional techniques that have a specific musical goal, which is achieved through different levels of the compositional process. Although it is quite difficult to identify these goals, I believe that Bach's aim is to profoundly elaborate different contrapuntal structures inside his compositional system, which he mentally categorized. Accordingly, the stretto technique (as a categorised type of contrapuntal virtuosity) is examined thoroughly to create a precise set of inherent constructive elements that can be identified and elaborated. Bach, in this way, consolidated for posterity some of the most essential rudiments of counterpoint technique.

\section{BIBLIOGRAPHY}

Alevizos, Konstantinos (2016), L'art de la Fugue de Johann Sebastian Bach, Saarbrücken, EUE.

Bach, Johann Sebastian (1926), Die Kunst der Fuge, BWV 1080, ed. Wolfgang Graeser, Leipzig, Breitkopf \& Härtel, Bach-Geselschaft, vol. 47.

Bagnal, Anne (1975), "The Simple Fugues," in Christoph Wolff (ed.), "Seminar Report. Bach's Art of Fugue, An Examination of the Sources," Current Musicology, n 19., pp. 59-61.

Bitsch, Marcel (1967), L'art de la fugue, Paris, Durand. , and Jean Bonfils (1981), La fugue, Paris, Presses Universitaires de France.

Butler, Gregory (1983), "Ordering Problems in J. S. Bach's 'Art of Fugue' Resolved," The Musical Quarterly, vol. 69, n' 1 (December), pp. 44-61.

Butler, Gregory, Stauffer, George, and Dalton Mary Green (eds) (2008), About Bach, Illinois, University of Illinois. 
Chailley, Jacques (1971), L'art de la fugue de J.S. Bach. Étude critique des sources. Remise en ordre du plan. Analyse de l'ouvre, Paris, A. Leduc.

Dentler, Hans-Eberhard (2000), L'arte della fuga di Johann Sebastian Bach, Milano, Skira.

Dickinson, Alan Edgar Frederic (1950), The Art of J. S. Bach, London, Hinrischen Edition. (1956), Bach's Fugal Works. With an Account of Fugue before and after Bach, London, I. Pitman.

Franck, Peter (2010), “'A Fallacious Concept.' Invertible Counterpoint at the Twelfth within the Ursatz," Music Theory Spectrum, vol. 32, n 2 (Fall), pp. 121-144.

Göncz, Zoltán (1991), "The Permutational Matrix in J. S. Bach's Art of Fugue. The Last Fugue Finished?," Studia Musicologica Academiae Scientiarum Hungaricae, T. 33, Fasc. 1/4 , pp. 109-119

(2012), Bach's Testament on the Philosophical and Theological Background of the Art of Fugue, Plymouth, The Scarecrow Press.

Harrison, Daniel (1990), "Rhetoric and Fugue. An Analytical Application," Music Theory Spectrum, vol. 12, $\mathrm{n}^{\mathrm{o}} 1$ (Spring), pp. 1-42.

Heinrich, Adel (1983), Bach's Die Kunst Der Fuge. A Living Compendium of Fugal Procedures, with a Motivic Analysis of All Fugues, Washington, University Press of America.

Higgs, James (1877), "Bach's 'Art of Fugue'," Proceedings of the Musical Association, pp. 45-73.

Houten, Kees Van, and Marinus Kasbergen (eds), (2003), Bach et le nombre; une recherche sur la symbolique des nombres et les fondements ésotériques de ceux-ci dans l'oeuvre de Johann Sebastian, Liège, Mardaga.

Kerman, Joseph (2005), The Art of Fugue. Bach Fugues for Keyboard, 1715-1750, Berkeley/London, University of California Press.

Kolneder, Walter (1983), Die Kunst der Fuge. Ein Mythos des 20. Jahrhunderts, Wilhelmshaven, Noetzel Florian.

Lester, Joel (2001), "Heightening Levels of Activity and J. S. Bach's Parallel-Section Constructions," Journal of the American Musicological Society, vol. 54, n 1 (Spring), pp. 49-96.

Levarie, Siegmund, and Arnold Merrick (1943), "Fugue and Form," Bulletin of the American Musicological Society, vol. 7 (October), pp. 15-17.

Mann, Alfred (1987), The Study of Fugue, New York, Dover Publications.

Rivera, Benito V. (1978), "Bach's Use of Hitherto Unrecognized Types of Countersubjects in the Art of Fugue," Journal of the American Musicological Society, vol. 31, no 2 (Summer), pp. 344-362.

Sheldon, David A. (1990), "The Stretto Principle. Some Thoughts on Fugue as Form," The Journal of Musicology, vol. 8, n 4 (Autumn), pp. 553-568.

Schleuning, Peter (1993) Johann Sebastian Bachs "Kunst der Fuge." Ideologien, Entstehung, Analyse, Kassel, Bärenreiter.

Tatlow, Ruth (1991), Bach and the Riddle of the Number Alphabet, New York, Cambridge University Press.

(2015), Bach's Numbers Compositional Proportion and Significance, New York, Cambridge University Press

Tovey, Donald ([1931]1974), A Companion to the Art of Fugue, New York, Oxford University Press.

Vartolo, Sergio (2008), Johann Sebastian Bach, Homo Universalis. Die Kunst Der Fugue, BWV 1080, Firenze, SPES.

Wiemer, Wolfgang (1977), Die wiederhergestellte Ordnung in Johann Sebastian Bachs Kunst der Fuge, Wiesbaden, Breitkopf \& Härtel.

(1981), "Eine unbekannte Frühfassung des 'Contrapunctus 2' im Autograph der Kunst der Fuge - mit einigen Anmerkungen zur Großform des Werks," Musikforschung, vol. 34, n 4 (OctoberDecember), pp. 413-422. 
Wolff, Christoph (1975), "The Last Fugue Unfinished?," in Christoph Wolff (ed.), "Seminar Report. Bach's Art of Fugue, An Examination of the Sources," Current Musicology, no 19, pp. 71-77.

\section{ANNEX}

i. Two-voice Stretto in Rectus (RR) in All Entry Distances (Half Note Level)

\begin{tabular}{|c|c|c|c|c|c|c|c|c|c|c|c|c|}
\hline \multicolumn{2}{|c|}{$\begin{array}{c}\text { Entry } \\
\text { Distance }\end{array}$} & 1 & 2 & 3 & 4 & 5 & 6 & 7 & 8 & 9 & 10 & 11 \\
\hline \multirow{2}{*}{ Half note } & \multirow[t]{2}{*}{$D$} & A & $\mathbf{F}$ & D & $\mathrm{C \#}$ & D & $\mathbf{F}$ & & & & & \\
\hline & & D & A & F & D & $\mathrm{CH}$ & D & F & & & & \\
\hline \multirow{2}{*}{ Whole note } & \multirow[t]{2}{*}{$D$} & \multirow[t]{2}{*}{ A } & $\mathbf{F}$ & D & $\mathrm{CH}$ & D & $\mathbf{F}$ & & & & & \\
\hline & & & D & A & $\mathrm{F}$ & D & $\mathrm{CH}$ & D & F & & & \\
\hline \multirow{2}{*}{$\begin{array}{c}\text { Dotted } \\
\text { Whole note }\end{array}$} & \multirow[t]{2}{*}{$D$} & \multirow[t]{2}{*}{$\mathbf{A}$} & \multirow[t]{2}{*}{$\mathbf{F}$} & D & $\mathrm{CH}$ & D & $\mathbf{F}$ & & & & & \\
\hline & & & & D & A & F & D & CH & D & F & & \\
\hline \multirow{2}{*}{$\begin{array}{c}\text { Double } \\
\text { Whole note }\end{array}$} & \multirow[t]{2}{*}{$D$} & \multirow[t]{2}{*}{ A } & \multirow[t]{2}{*}{$\mathbf{F}$} & \multirow[t]{2}{*}{ D } & $\mathrm{C \#}$ & D & F & & & & & \\
\hline & & & & & D & $\mathrm{A}$ & F & D & C\# & D & F & \\
\hline $\begin{array}{l}\text { Double } \\
\text { Whole }\end{array}$ & \multirow[t]{2}{*}{$D$} & \multirow[t]{2}{*}{$\mathbf{A}$} & \multirow[t]{2}{*}{$\mathbf{F}$} & \multirow[t]{2}{*}{ D } & \multirow[t]{2}{*}{ CH } & D & $\mathbf{F}$ & & & & & \\
\hline $\begin{array}{c}\text { note } \\
+ \\
\text { Half note }\end{array}$ & & & & & & D & $\mathrm{A}$ & F & D & $\mathrm{CH}$ & D & $F$ \\
\hline \multirow{2}{*}{$\begin{array}{c}\text { Dotted } \\
\text { Double } \\
\text { Whole } \\
\text { note }\end{array}$} & \multirow[t]{2}{*}{$D$} & \multirow[t]{2}{*}{$\mathbf{A}$} & \multirow[t]{2}{*}{$\mathbf{F}$} & \multirow[t]{2}{*}{ D } & \multirow[t]{2}{*}{ C\# } & \multirow[t]{2}{*}{ D } & $\mathbf{F}$ & & & & & \\
\hline & & & & & & & D & $\mathrm{A}$ & F & D & CH & D \\
\hline
\end{tabular}

ii. Two-voice Stretto in Inversus (II) in All Entry Distances (Half Note Level)

\begin{tabular}{|c|c|c|c|c|c|c|c|c|c|c|c|c|}
\hline \multicolumn{2}{|c|}{$\begin{array}{c}\text { Entry } \\
\text { Distance }\end{array}$} & 1 & 2 & 3 & 4 & 5 & 6 & 7 & 8 & 9 & 10 & 11 \\
\hline \multirow{2}{*}{ Half note } & \multirow[t]{2}{*}{$\boldsymbol{A}$} & D & $\mathbf{F}$ & $\mathbf{A}$ & $\mathbf{B b}$ & A & F & & & & & \\
\hline & & A & D & F & $\mathrm{A}$ & $\mathrm{Bb}$ & A & F & & & & \\
\hline \multirow{2}{*}{ Whale nate } & \multirow[t]{2}{*}{$\boldsymbol{A}$} & \multirow[t]{2}{*}{ D } & $\mathbf{F}$ & $\mathbf{A}$ & Bb & A & $\mathbf{F}$ & & & & & \\
\hline & & & A & D & F & A & $\mathrm{Bb}$ & $\mathrm{A}$ & F & & & \\
\hline \multirow{2}{*}{$\begin{array}{c}\text { Dotted } \\
\text { Whole note }\end{array}$} & \multirow[t]{2}{*}{$A$} & \multirow[t]{2}{*}{ D } & \multirow[t]{2}{*}{$\mathbf{F}$} & A & Bb & A & $\mathbf{F}$ & & & & & \\
\hline & & & & A & D & F & A & $\mathrm{Bb}$ & A & F & & \\
\hline \multirow{2}{*}{$\begin{array}{l}\text { Double } \\
\text { Whale note }\end{array}$} & \multirow[t]{2}{*}{$\boldsymbol{A}$} & \multirow[t]{2}{*}{ D } & \multirow[t]{2}{*}{$\mathbf{F}$} & \multirow[t]{2}{*}{$\mathbf{A}$} & $\mathbf{B b}$ & A & $\mathbf{F}$ & & & & & \\
\hline & & & & & $\mathrm{A}$ & D & F & A & $\mathrm{Bb}$ & A & F & \\
\hline \multirow{2}{*}{$\begin{array}{c}\text { Double } \\
\text { Whole } \\
\text { note } \\
+ \\
\text { Half note }\end{array}$} & \multirow[t]{2}{*}{$A$} & \multirow[t]{2}{*}{ D } & \multirow[t]{2}{*}{$\mathbf{F}$} & \multirow[t]{2}{*}{$\mathbf{A}$} & \multirow[t]{2}{*}{ Bb } & A & $\mathbf{F}$ & & & & & \\
\hline & & & & & & A & D & F & A & $\mathrm{Bb}$ & A & F \\
\hline \multirow{2}{*}{$\begin{array}{c}\text { Dotted } \\
\text { Double } \\
\text { Whole } \\
\text { note }\end{array}$} & \multirow[t]{2}{*}{$A$} & \multirow[t]{2}{*}{ D } & \multirow[t]{2}{*}{$\mathbf{F}$} & \multirow[t]{2}{*}{ A } & \multirow[t]{2}{*}{ Bb } & \multirow[t]{2}{*}{ A } & $\mathbf{F}$ & & & & & \\
\hline & & & & & & & A & D & F & $\mathrm{A}$ & $\mathrm{Bb}$ & A \\
\hline
\end{tabular}


iii. Two-voice Stretto in Rectus-Inversus (RI) in All Entry Distances (Half Note Level)

\begin{tabular}{|c|c|c|c|c|c|c|c|c|c|c|c|c|}
\hline \multicolumn{2}{|c|}{$\begin{array}{c}\text { Entry } \\
\text { Distance }\end{array}$} & 1 & 2 & 3 & 4 & 5 & 6 & 7 & 8 & 9 & 10 & 11 \\
\hline \multirow{2}{*}{ Simultaneous } & D & A & $\mathbf{F}$ & D & C\# & D & $\mathbf{F}$ & & & & & \\
\hline & A & D & F & A & $\mathrm{Bb}$ & A & F & & & & & \\
\hline \multirow{2}{*}{ Half note } & D & A & $\mathbf{F}$ & D & CH & D & $\mathbf{F}$ & & & & & \\
\hline & & A & D & F & $\mathrm{A}$ & $\mathrm{Bb}$ & $\mathrm{A}$ & F & & & & \\
\hline \multirow{2}{*}{ Whole note } & D & A & $\mathbf{F}$ & D & CH & D & $\mathbf{F}$ & & & & & \\
\hline & & & A & D & F & $\mathrm{A}$ & $\mathrm{Bb}$ & A & F & & & \\
\hline \multirow{2}{*}{$\begin{array}{c}\text { Dotted Whole } \\
\text { note }\end{array}$} & D & A & $\mathbf{F}$ & D & CH & D & $\mathbf{F}$ & & & & & \\
\hline & & & & A & D & F & A & $\mathrm{Bb}$ & A & F & & \\
\hline \multirow{2}{*}{$\begin{array}{c}\text { Double } \\
\text { Whole note }\end{array}$} & D & A & $\mathbf{F}$ & D & C\# & D & $\mathbf{F}$ & & & & & \\
\hline & & & & & A & D & F & $\mathrm{A}$ & $\mathrm{Bb}$ & $\mathrm{A}$ & F & \\
\hline \multirow{2}{*}{$\begin{array}{c}\text { Double Whole } \\
\text { note } \\
+ \\
\text { Half note }\end{array}$} & D & A & $\mathbf{F}$ & D & C\# & D & $\mathbf{F}$ & & & & & \\
\hline & & & & & & $\mathrm{A}$ & D & F & $\mathrm{A}$ & $\mathrm{Bb}$ & $\mathrm{A}$ & $\mathrm{F}$ \\
\hline $\begin{array}{c}\text { Dotted } \\
\text { Double Whole } \\
\text { note }\end{array}$ & D & $\mathbf{A}$ & $\mathbf{F}$ & D & C\# & D & $\begin{array}{l}\text { F } \\
\mathrm{A}\end{array}$ & D & F & A & $\mathrm{Bb}$ & A \\
\hline
\end{tabular}

iv. Two-voice Stretto in Inversus-Rectus (IR) in All Entry Distances (Half Note Level)

\begin{tabular}{|c|c|c|c|c|c|c|c|c|c|c|c|c|}
\hline \multicolumn{2}{|c|}{$\begin{array}{c}\text { Entry } \\
\text { Distance }\end{array}$} & 1 & 2 & 3 & 4 & 5 & 6 & 7 & 8 & 9 & 10 & 11 \\
\hline \multirow{2}{*}{ Simultaneous } & A & D & $\mathbf{F}$ & A & Bb & $\mathbf{A}$ & $\mathbf{F}$ & & & & & \\
\hline & D & A & F & D & CH & D & F & & & & & \\
\hline \multirow{2}{*}{ Half note } & A & D & F & A & Bb & $\mathbf{A}$ & F & & & & & \\
\hline & & D & A & F & D & C\# & D & F & & & & \\
\hline \multirow{2}{*}{ Whole note } & A & D & $\mathbf{F}$ & A & Bb & A & $\mathbf{F}$ & & & & & \\
\hline & & & D & A & F & D & $\mathrm{CH}$ & D & F & & & \\
\hline \multirow{2}{*}{$\begin{array}{l}\text { Dotted Whole } \\
\text { note }\end{array}$} & A & D & $\mathbf{F}$ & A & Bb & $\mathbf{A}$ & F & & & & & \\
\hline & & & & D & A & F & D & C\# & D & F & & \\
\hline \multirow{2}{*}{$\begin{array}{c}\text { Double } \\
\text { Whole note }\end{array}$} & A & D & $\mathbf{F}$ & A & Bb & A & $\mathbf{F}$ & & & & & \\
\hline & & & & & D & A & F & D & C\# & D & F & \\
\hline \multirow{2}{*}{$\begin{array}{c}\text { Double Whole } \\
\text { note } \\
+ \\
\text { Half note }\end{array}$} & A & D & $\mathbf{F}$ & A & Bb & A & $\mathbf{F}$ & & & & & \\
\hline & & & & & & D & A & F & D & C\# & D & F \\
\hline \multirow{2}{*}{$\begin{array}{c}\text { Dotted } \\
\text { Double Whole } \\
\text { note }\end{array}$} & A & D & $\mathbf{F}$ & A & $\mathbf{B b}$ & $\mathbf{A}$ & $\mathbf{F}$ & & & & & \\
\hline & & & & & & & D & $\mathrm{A}$ & $\mathrm{F}$ & D & $\mathrm{CH}$ & D \\
\hline
\end{tabular}


ia. Two-voice Stretto in Rectus (RR) in All Entry Distances (Half Note Level)

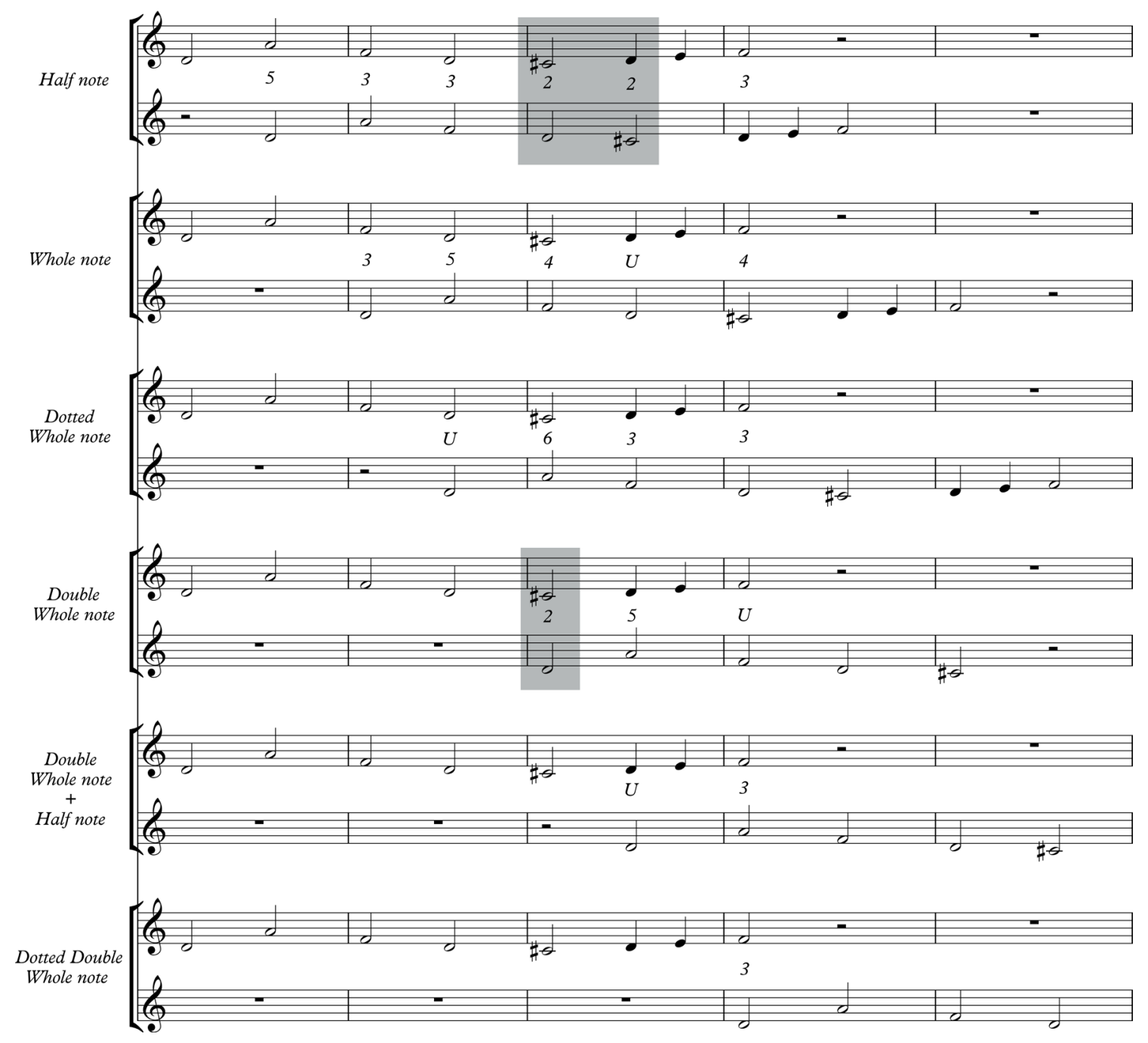


iia. Two-voice Stretto in Inversus (II) in All Entry Distances (Half Note Level)

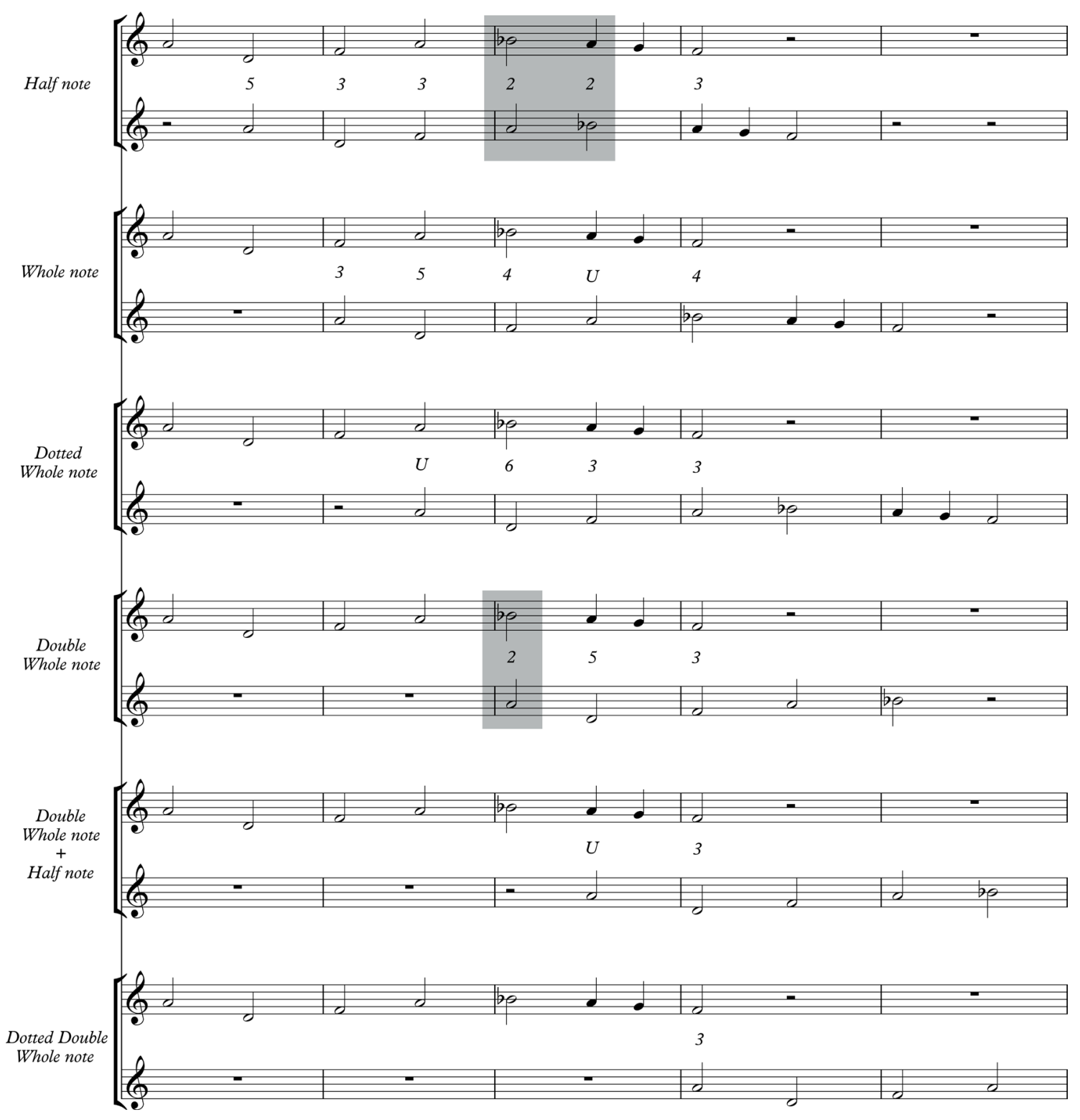


iiia. Two-voice Stretto in Rectus-Inversus (RI) in All Entry Distances (Half Note Level)

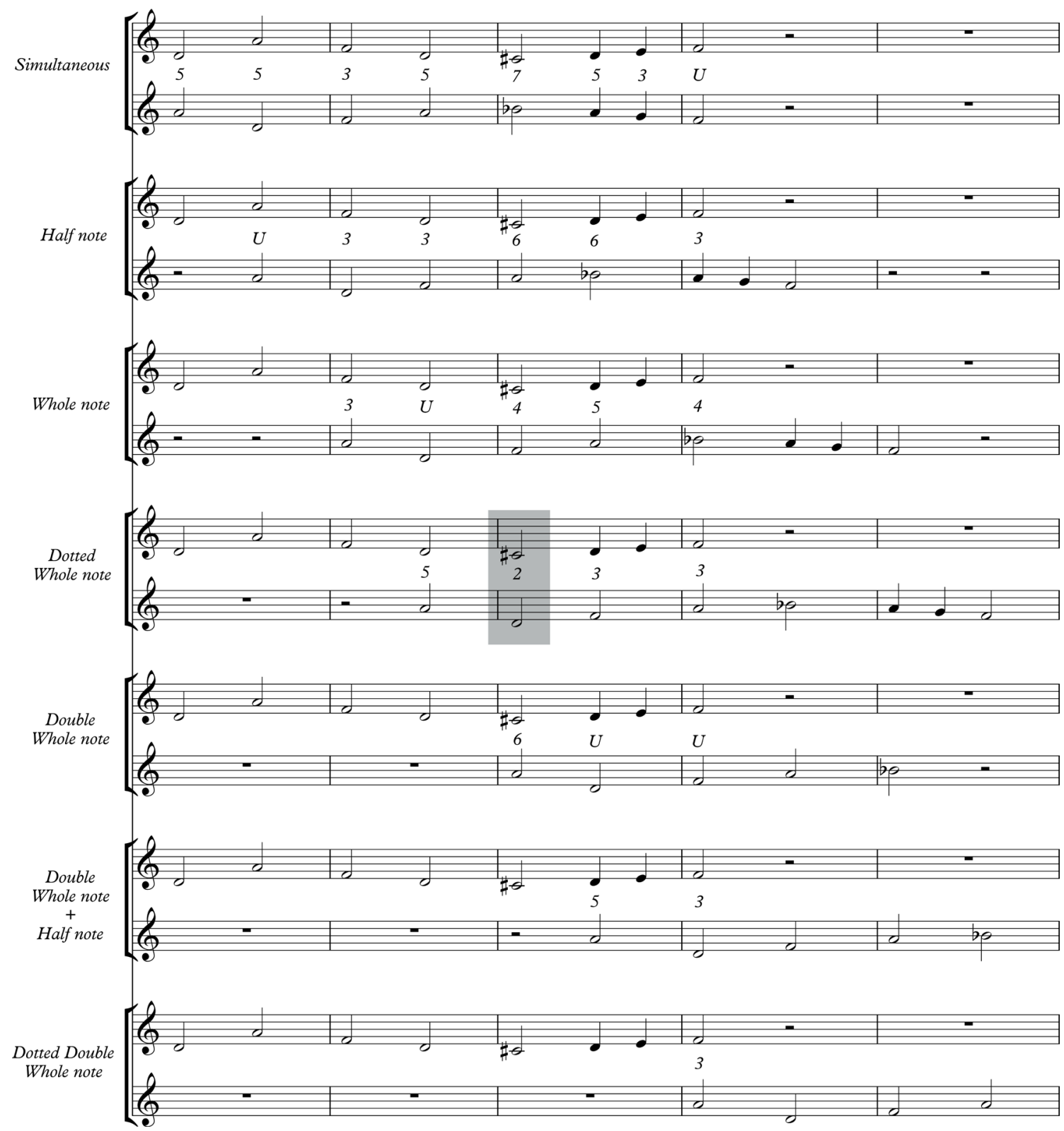


iva. Two-voice Stretto in Inversus-Rectus (IR) in All Entry Distances (Half Note Level)

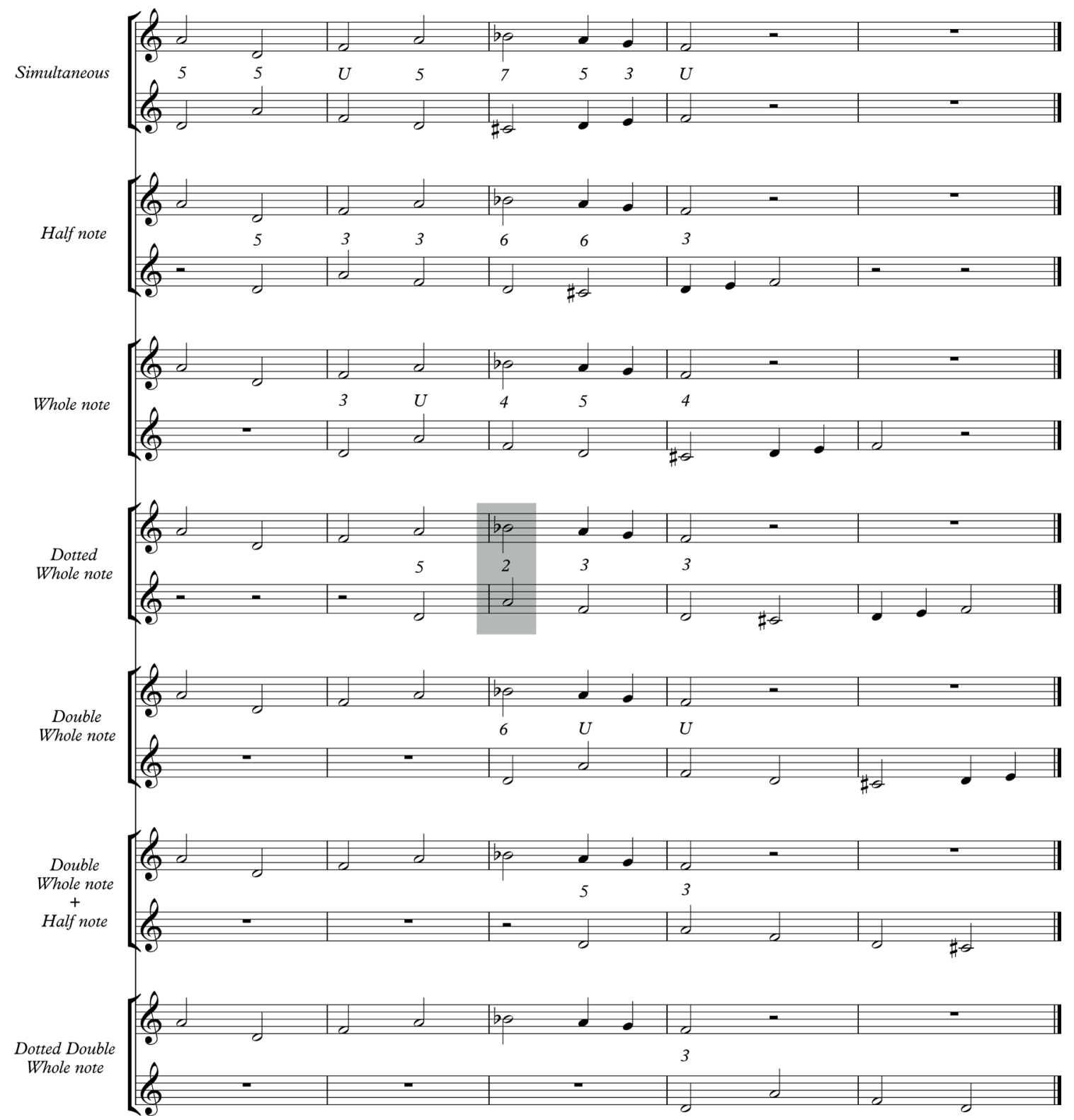

